\title{
EL FUTURO DE CUBA A LA LUZ DE SUS FUERZAS ARMADAS* ${ }^{*}$
}

\author{
MARCOS P. MOLOEZNIK GRUER*
}

\begin{abstract}
RESUMEN
Las fuerzas armadas revolucionarias de Cuba (FAR) constituyen un actor clave para el futuro político de la isla, por lo que a partir de un marco teórico-analítico del instrumento militar, se intenta someter a análisis la naturaleza de las FAR así como poner a consideración del lector escenarios a futuro.
\end{abstract}

Palabras clave: Poder militar, fuerzas armadas, Cuba, expansión del rol institucional.

\section{THE FUTURE OF CUBA UNDER THE ARMED FORCES PERSPECTIVE}

\begin{abstract}
The revolutionary armed forces of Cuba (FAR) are undoubtedly a key agent for the political future of the island, with this fact as an starting point, this article presents an analysis from theoretical and analytical framework of the military instrument, to foresee the FAR of Cuba as an actor and the role it may play in possible future scenarios.
\end{abstract}

Key words: Military power, armed forces, Cuba, expansion of the institutional role.

\footnotetext{
* Una versión previa se publicó bajo el título Las Fuerzas Armadas Revolucionarias de Cuba entre el pasado y el futuro; en, Cuba: ¿Quo vadis?, DEMIBCZ, Katarzyna (Editora), Varsovia, Centro de Estudios Latinoamericanos, Universidad de Varsovia, Publicación financiada por el National Science Centre (Centro Nacional de Ciencia de Polonia) en el marco del proyecto "¿Quo vadis Cuba? Implicaciones para Europa y Polonia" UMO-2011/01/B/HS4/03233, ISBN 978-83-62992-11-9, 2013, pp. 149-166.

** Profesor-Investigador Titular "C" Tiempo Completo, Departamento de Estudios Políticos, Centro Universitario de Ciencias Sociales y Humanidades, Universidad de Guadalajara. Profesor Huésped de las Universidades de Colonia y Libre de Berlín, Alemania; Nacional de Rosario, Buenos Aires y El Salvador, Argentina; Alcalá, España; Leiden, Holanda; y, Varsovia, Polonia. Profesor Invitado del Colegio Interamericano de Defensa y del Colegio de la Defensa Nacional de Honduras, de 2008 a 2010, así como del Instituto Internacional de Derecho Humanitario, Sanremo, Italia, de 2013 a 2015, inclusive.mmoloeznik@yahoo.es

¿ Fecha de recepción: 050514

Fecha de aceptación: 040615
} 


\section{Breves palabras iniciales}

\section{Para el órgano de difusión de la Arquidiócesis de La Habana1:}

"Si una entidad tiene en sus manos la posibilidad de influir en los derroteros futuros de la nación será este cuerpo bien organizado del cual forman parte decenas de miles de hombres y mujeres en calidad de oficiales profesionales; centenares de miles de soldados y efectivos de la reserva; y una masa incalculable de familiares de estas personas, las cuales, indirectamente, poseen un ligamen muy fuerte con la institución".

A partir de este reconocimiento, la presente contribución intenta dilucidar el futuro de Cuba desde las fuerzas armadas en tanto institución; para lo cual se explora la naturaleza de las denominadas fuerzas armadas revolucionarias (FAR) mediante un marco teórico-analítico desarrollado por un académico chileno, otrora director de la Academia de Guerra de del Ejército y profesor de Seguridad Nacional del Centro Hemisférico de Estudios de Defensa, de la Universidad Nacional de la Defensa de Washington, D.C.

\section{Marco teórico-analítico-metodológico: poder militar y fuerzas armadas}

Tradicionalmente se concibe al factor militar como un componente del poder nacional ${ }^{2}$. Se trata, en otros términos, de lo que Nye Jr. ${ }^{3}$ denomina, en el ámbito de las relaciones internacionales, hard power (poder duro); en contraste con el soft power (poder blando) que caracteriza el comportamiento de los Estadosnación en la arena internacional ${ }^{4}$.

Precisamente, se reconoce al poder militar -encarnado en las fuerzas armadas-como el símbolo de la soberanía nacional y máxima intensidad de uso de la fuerza (ultima ratio del Estado) ${ }^{5}$.

1 GONZÁLEZ Mederos, Lenier, Las fuerzas armadas y el futuro de Cuba; en, Espacio Laical (Suplemento Digital de la Arquidiócesis de La Habana), número 224, marzo de 2013, pp. 1 - 3.

2 KNORR, Klaus E., El poder de las naciones, Buenos Aires, Editorial de Belgrano, 1981, pp. 169 y ss.

3 NYE Jr, Joseph. S., Get Smart-Combining Hard and Soft Power. Foreign Affairs, 2009, p.160.

4 ABREU, Ricardo, Power and Politics in International Relations Theories:A Strategic Framework Approach. European and International dimension of policy-making Professor Michael Bauer, Instituto Universitário de Lisboa, January 2013, p. 39; disponible en; http://es.scribd.com/doc/122657199/Power-and-Politicsin-International-Relations-Theories-A-Strategic-Framework-Approach <consultado por última vez el 18 de agosto de 2013>.

5 Para mayores detalles; ver, MOLOEZNIK, Marcos Pablo, Seguridad y uso de la fuerza en el Estado contemporáneo (una interpretación mexicana sobre los instrumentos coercitivos estatales); en, Revista del Centro de Estudios Latinoamericanos (CESLA), Universidad de Varsovia, (6) 2004, pp. 29-36. 
Para Beaufre, cuando el conductor político opta por el componente militar del poder nacional, nos encontramos ante la estrategia en el modo de acción directo, la cual6:

"<...> está fundada por espacio sobre la búsqueda de la decisión, por el empleo o la amenaza de las fuerzas militares consideradas como el medio principal. El hecho que se las emplee presupone, por lo tanto, que en el análisis del nivel de las decisiones políticas, se ha llegado a la conclusión general que las fuerzas militares representan el medio más eficaz. Esta conclusión reposa, en general, por una parte, sobre la existencia o la posibilidad de una superioridad muy neta en el campo militar; por otra parte, sobre la constatación que ningún otro medio sería bastante eficaz".

Así, las fuerzas armadas son el instrumento coercitivo por excelencia del Estado-nación y responsables de velar por la soberanía nacional y la integridad territorial.

En tanto que, con el objeto de analizar al brazo armado de la República de Cuba, conviene revisar el andamiaje teórico-metodológico desarrollado por Jaime García Covarrubias ${ }^{7}$. De esta manera, siguiendo al autor citado ${ }^{8}$.

“...las Fuerzas Armadas (como instrumentos de la defensa) tienen una naturaleza (fueron creadas para cumplir una misión) se les ha dotado de capacidades (para ser eficaces y eficientes en el cumplimiento de la misión) y tienen un marco constitucional que las ordena. Lo lógico es emplearlas dentro de esos cánones. A su vez, el propio Estado tendrá que desarrollar las capacidades específicas para resolver los diferentes tipos de problemas o amenazas...".

Además, el poder armado es simplemente una herramienta del gobierno, un instrumento de la política? .

6 BEAUFRE, André, La Estrategia en el modo de acción, Buenos Aires, Pleamar, 1973, p. 129.

7 GARCÍA Covarrubias, Jaime, Transformación de la Defensa: El Caso de EE.UU. y su Aplicación en Latinoamérica; en, Military Review, The Professional Journal of the U.S. Army, Edición Hispanoamericana, Fort Leavenworth, Kansas, U.S. Army Combined Arms Center, Marzo-Abril 2005; pp. 23-30.

8 Ibidem, p. 24.

9 CLAUSEWITZ, Karl von, De la Guerra (III). Libro VIII, "Plan de una guerra" Capítulo VI, "Influencia del objetivo político sobre el propósito militar" y "La guerra como instrumento de la política", México, Editorial Diógenes, S.A., 1973, pp. 349-359. 


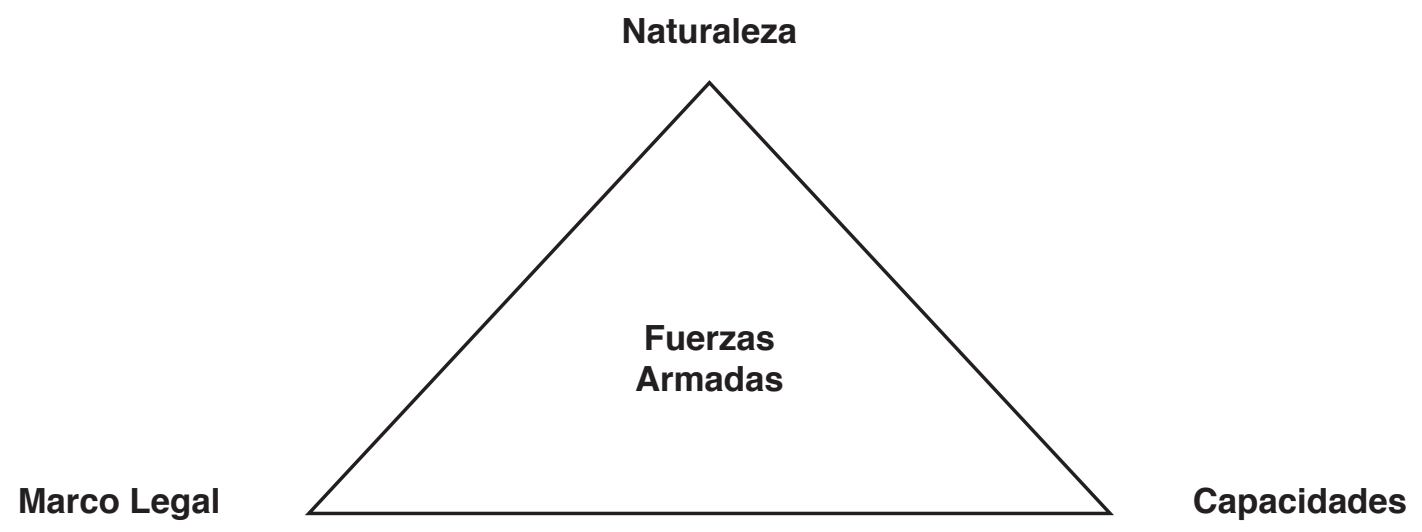

Recapitulando, tres son los conceptos fundamentales en los que se afirma cualquier instrumento militar ${ }^{10}$ :

a) Su naturaleza, es decir, para qué nacieron o cuál es la tarea que la sociedad le confirió.

b) Un marco normativo, dotado por el Estado de Derecho.

c) Ciertas capacidades, entregadas por el Estado, para el cumplimiento de las tareas naturales de conformidad con su marco jurídico.

Se trata de tres ejes básicos que interactúan y, por ende, la modificación de uno impacta sobre el resto. Mientras que en el escenario estratégico actual se vislumbra para el sector de la defensa el cumplimiento de cuatro misiones principales, a saber ${ }^{11}$ :

a) Convencionales, entendida como la resolución de las amenazas tradicionales o un eventual ataque militar.

b) No convencionales, de la mano de las denominadas nuevas amenazas.

c) Las que se corresponden con los compromisos estratégicos que asume el país, tanto con sus aliados, como con la comunidad internacional; cuyo significado es la necesaria vinculación o nexo entre la política exterior y la política de defensa.

d) Las contribuyentes al desarrollo nacional. Esta misión responde a los roles latentes de las fuerzas armadas, producto de la génesis y tradición de los

10 GARCÍA Covarrubias, Jaime, op. cit., pp. 25 y 28.

11 Ibidem, p. 25. 
Estados-nación en Latinoamérica; antítesis de las manifiestas, que vienen dadas por el marco jurídico.

e) Adicionalmente, y como quinta tarea, se suman las funciones de seguridad pública.

Ahora bien, cabe destacar que, tradicionalmente, en la mayoría de los países existe una clara diferenciación entre la defensa nacional y la seguridad pública e interior ${ }^{12}$, puesto que "El primero y principal objeto de un ejército es, por supuesto, la defensa contra enemigos externos"13. Tampoco debe perderse de vista que cada país jerarquiza estas misiones en ejercicio de su soberanía, de acuerdo a su particular situación y amenazas.

\section{Naturaleza y misiones de las Fuerzas Armadas Revolucionarias de Cuba (FAR)}

Las FAR nacen oficialmente el 16 de octubre de 1959; siendo su origen el denominado Ejército Rebelde, brazo armado de la guerra de liberación librada desde el 2 de diciembre de 1956 hasta el 1 de enero de 1959; de ahí su atipicidad, al ser producto de un movimiento revolucionario ${ }^{14}$.

Tampoco se debe soslayar su paternidad, puesto que se reconoce en Raúl Castro Ruz a su arquitecto, quien a los 28 años de edad asume como titular del flamante Ministerio de las FAR (MINFAR) ${ }^{15}$.

En lo que respecta a sus misiones, históricamente en orden de importancia son:

a) Convencionales: entendida como la defensa nacional; dado que la Constitución de la República de Cuba consagra el "Derecho de combatir por todos los medios"16, así como que el principio de que "La defensa de la patria socialista es el más grande honor y el deber supremo de cada cubano"17.

12 MURRAY, Douglas J. \& VIOTTI, Paul R., The Defense Policies of Nations (A Comparative Study), Baltimore and London, The Johns Hopkins University Press, 1994.

13 STERN, Frederick Martin, El Ejército Ciudadano, Biblioteca del Oficial, Volumen 509, Buenos Aires, Círculo Militar, 1961, p. 33.

14 Para mayores detalles; ver, http://www.ecured.cu/index.php/FAR <consultada por última vez el 7 de mayo de 2014>.

15 Sobre su biografía y vida; ver, por ejemplo, http://www.biografiasyvidas.com/biografia/c/castro_raul.htm y http://www.ecured.cu/index.php/Ra\%C3\%BAl_Castro <consultados por última vez el 7 de mayo de 2014>.

16 GOBIERNO DE LA REPÚBLICA DE CUBA, Constitución de la República de Cuba, La Habana, Cuba Debate, 2013, Artículo 3; disponible en, http://www.cubadebate.cu/cuba/constitucion-republica-cuba/ <consultado por última vez el 18 de agosto de 2013>.

17 Ibidem, Artículo 65. 
Tal como se pone de relieve en párrafos anteriores, la principal misión de las FAR es la defensa nacional, a partir de una postura defensiva-disuasiva, basada en la doctrina de resistencia popular generalizada para imponerle al agresor una guerra de desgaste material y psicológico con costos inaceptables; la cual tuvo su bautismo de fuego en Playa Girón (Bahía de Cochinos) el 17 abril de 1961, con la decisiva actuación de las milicias y el apoyo de la Unión de Repúblicas Socialistas Soviéticas (URSS) ${ }^{18}$, que se extendió a lo largo de tres décadas (1961-1991).

\section{Así, de acuerdo con Da Silva y Johnson"19:}

"Los aspectos fundamentales de la ayuda soviética se referían al apoyo económico y militar. Más allá de la protección frente a Estados Unidos, tal apoyo convirtió al país en una de las principales potencias militares de América Latina, considerando la calidad del equipamiento, el entrenamiento y la capacidad de intervención en múltiples conflictos de diferente naturaleza (guerras convencionales, operaciones especiales, guerra de guerrillas, etc.)".

En otras palabras, la doctrina militar cubana ${ }^{20}$ :

"Por su esencia es defensiva, y se basa en la disuasión, entendida como la evidencia de que el costo político, material y humano de una agresión militar contra Cuba sería prohibitivo y carecería de perspectiva de triunfo. Se adopta para un período dado, se perfecciona periódicamente, y se cambia por una nueva cuando ocurren transformaciones trascendentes en las condiciones que la determinan. La actual está vigente desde la década de los 80 ".

Se trata de la denominada guerra de todo el pueblo, que ${ }^{21}$ :

"Es la concepción estratégica para la defensa nacional, que resume la experiencia histórica de la nación en lo tocante a enfrentamientos contra enemigos numérica y tecnológicamente superiores. Se basa en el empleo más variado y eficiente de todos los recursos materiales y morales de la sociedad, organizados en el Sistema Defensivo Territorial, como sustento de la capacidad defensiva del Estado. Es el fundamento de la Doctrina Militar del Estado Cubano y expresa la solución de masas dada por la dirección de

18 Sobre este hito histórico en el marco de la Guerra Fría; ver, http://www.mgar.net/cuba/cochinos.htm y http:// www.ecured.cu/index.php/Invasi\%C3\%B3n_por_Playa_Gir\%C3\%B3n <consultados por última vez el 7 de mayo de 2014>.

19 DA SILVA, Marcos Antonio y JOHNSON, Guillermo A., As Forças Armadas Revolucionárias cubanas (FAR) e o mundo pós guerra-fria: um caso excepcional?, trabajo inédito y aceptado para ser publicado por una revista universitaria, proporcionado por Marcos Antonio da Silva, Profesor de Ciencia Política de la Universidade Federal do Rio Grande do Norte, Brasil, 2013, p. 2, traducción libre del autor.

20 GOBIERNO DE LA REPÚBLICA DE CUBA, Doctrina Militar Cubana; disponible en, http://www.cubagob.cu/ otras_info/minfar/doctrina/doctrina_militar.htm <consultado por última vez el 18 de agosto de 2013>.

21 Ibidem. 
la Revolución a los problemas de la defensa nacional. Suele resumirse al afirmar que, en caso de una agresión militar en gran escala contra Cuba, cada ciudadano tendrá un medio, un lugar y una forma de enfrentar al enemigo hasta lograr la victoria".

En síntesis, todo el esfuerzo militar se dedica estrictamente a la defensa del territorio del país. El carácter defensivo de las acciones y la resistencia popular generalizada como vía de enfrentar una agresión militar extranjera, constituyen así el núcleo de la concepción de la Guerra de Todo el Pueblo²2, lo que, para las FAR, se fundamenta en un axioma que a la letra reza: "solo con la fuerza del pueblo se pueden librar y ganar las batallas a favor de una causa justa; pero para vencer, toda la población necesita prepararse, instruirse y entrenarse en aras de combatir eficientemente"23. Es, en otras palabras, lo que denominan "pueblo uniformado", que se desprende de la doctrina de Camilo Cienfuegos ${ }^{24}$.

Cabe señalar que la defensa nacional se prepara y realiza bajo la dirección del Partido Comunista de Cuba, de conformidad con la Ley $N^{\circ} 75$ de la Defensa Nacional; se trata del compromiso de combatir al agresor, bajo la concepción estratégica-militar de la guerra de todo el pueblo, basada en la prolongación de los conflictos.

b) Compromisos internacionales: misión denominada de solidaridad; basada en la Carta Magna que reconoce la legitimidad de las luchas por la liberación nacional25.

\section{Tal como lo destacan Da Silva y Johnson'26:}

"No obstante una actuación condicionada por el contexto de la guerra fría (y la necesaria ayuda soviética) el ejército cubano actuó entrenando organizaciones revolucionarias o interviniendo directamente en importantes conflictos en América Latina (Nicaragua y Granada, entre otros) y en África

22 Sobre la evolución de la concepción de la Defensa en Cuba, incluyendo los tradiciones escenarios de invasión contemplados en la planeación militar; ver, KLEPAK, Hal, Cuba's Military 1990-2005: Revolutionary Soldiers during Counter-Revolutionary Times, London, Palgrave Macmillan, 2005; en particular, Chapter 9 The Military Defense of Cuba: But Can the FAR still Deter?, pp. 241-270.

23 GOBIERNO DE LA REPÚBLICA DE CUBA, Fundamentos de la Defensa Nacional; disponible en, http://www. cubagob.cu/otras_info/minfar/fundamentos/fundamentos1.htm <consultado por última vez el 7 de marzo de 2015>.

24 JUVENTUD REBELDE, Camilo Cienfuegos: fuerza y pasión de su pensamiento revolucionario, 24 de octubre de 2014; disponible en, http://www.juventudrebelde.cu/cuba/2014-10-24/camilo-cienfuegos-fuerza-ypasion-de-su-pensamiento-revolucionario/ <consultado por última vez el 7 de marzo de 2015>.

25 GOBIERNO DE LA REPÚBLICA DE CUBA, Constitución de la República de Cuba, La Habana, Cuba Debate, 2013, Artículo 12; disponible en, http://www.cubadebate.cu/cuba/constitucion-republica-cuba/ <consultado por última vez el 18 de agosto de 2013>.

26 DA SILVA, Marcos Antonio y JOHNSON, Guillermo A., Vid Supra, p. 2. 
(Angola y Mozambique, entre otros), jugando un papel importante en los procesos revolucionarios de los continentes mencionados, en los procesos de descolonización y en la derrota de la expansión del régimen del apartheid sudafricano. De esta forma, como lo apuntan innumerables estudiosos, transformó en una de las fuerzas mejor entrenadas y más profesionales de la región".

Es decir, más allá de la defensa nacional, que contempla el estado de guerra o la guerra, a la sazón como la situación excepcional de mayor trascendencia que se declara en todo el territorio nacional, con el objetivo de emplear todas las fuerzas y recursos de la sociedad y el Estado para mantener y defender la integridad y soberanía de la Patria ${ }^{27}$; durante décadas, el aparato militar cubano participó en operaciones de combate bajo la consigna del internacionalismo proletario en misiones de solidaridad ${ }^{28}$. Se trató de las siguientes cinco: a) República Democrática y Popular de Argelia, b) República Árabe Siria, c) República Popular de Angola, d) República Popular del Congo y e) República de Etiopía ${ }^{29}$.

a) Argelia: desarrollada entre octubre de 1963 y abril de 1964, respondiendo a los requerimientos del entonces líder argelino Ahmed Ben Bella ante la agresión perpetrada por el Ejército marroquí. El contingente cubano estuvo integrado por 686 efectivos, en composición de un batallón de tanques y unidades de artillería y de servicios de apoyo. El mando argelino-cubano planificó y organizó una operación ofensiva contra el territorio marroquí, denominada Operación Dignidad, la cual no fue ejecutada, ya que se llegó a un arreglo, después del cual las tropas retornaron a Cuba.

b) Siria: el 28 octubre de 1973 -a poco de finalizada la guerra de Yom KippurCuba envió 746 combatientes, a solicitud del gobierno sirio y con motivo del fracaso de la ofensiva del 6 de octubre de 1973 contra el Estado de Israel. Cabe señalar que con los efectivos cubanos se conformó un Regi-

27 GOBIERNO DE LA REPÚBLICA DE CUBA, La Ley No 75 de la Defensa Nacional, La Habana, Cuba Defensa, 2012; disponible en, http://www.cubadefensa.cu/?q=ley75 <consultado por última vez el 18 de agosto de 2013>.

28 El legendario comandante Ernesto "Che" Guevara es considerado pionero y punta de lanza de las misiones internacionalistas, ya que en 1965 -dos años antes de ser abatido en Bolivia, donde intentó poner en práctica la denominada Teoría del Foco, con el objeto de crear varios Vietnam en Latinoamérica (MOLOEZNIK, 2012: 95 y ss.)- solicitó a Fidel Castro su autorización para viajar al continente africano, donde estableció contacto con diversos grupos guerrilleros, de los que destacó el Movimiento Popular para la Liberación de Angola (MPLA) bajo la entonces dirección de Agostino Neto. En aquellos años, el "Che" peleó en el Congo de Patricio Lumumba (hoy Zaire) así como en Tanzania. Ver, OROZCO, Román, Cuba Roja (Cómo viven los cubanos con Fidel Castro), Buenos Aires, Javier Vergara, 1993, pp. 113-114.

29 Tomado de; Coronel (R) SAUTIÉ Mohedano, Pedro y Teniente Coronel PÉREZ San Miguel, Alfredo, Misiones militares internacionalistas cumplidas por las Fuerzas Armadas Revolucionarias de la República de Cuba; en CUBA DEFENSA (2012), http://www.cubadefensa.cu/?q=misiones-militares\&b=d3 <consultado por última vez el 18 de agosto de 2013>. 
miento de Tanques, que después se integró en la 47 Brigada de Tanques (BT) cubano-siria, para volver posteriormente a su composición inicial. El 29 de octubre, un día después del arribo del primer contingente de cubanos, Siria aceptó la Resolución 338 del Consejo de Seguridad de la ONU que decretaba el cese al fuego entre árabes e israelíes. No obstante, el mando cubano-sirio planificó seis misiones de combate a cumplir por la 47 BT combinada, las que no fueron necesarias ejecutar. El 15 de enero de 1975 el contingente militar cubano partió de regreso a Cuba, adonde arribó el 4 de febrero, dándose por concluida la misión ${ }^{30}$.

c) Angola: la misión denominada Operación Carlota ${ }^{31}$ fue la más importante cumplida por las FAR, ya que se extendió desde agosto de 1975 hasta mayo de 1991. Tuvo lugar respondiendo a la solicitud de ayuda que formuló al Gobierno cubano el líder histórico del Movimiento para la Liberación de Angola (MPLA) Agostinho Neto, ante la agresión perpetrada por las fuerzas armadas de Sudáfrica y de Zaire, apoyadas por los grupos armados FNLA y la UNITA de Angola y mercenarios blancos, para impedir la independencia de Angola, derrotar al MPLA y ocupar el país. A lo largo de esos casi dieciséis años los internacionalistas cubanos participaron, conjuntamente con los combatientes de las FAPLA y la SWAPO, en las más importantes acciones de combate libradas en Angola. En total, cumplieron misión en Angola 337.033 militares y unos 50.000 colaboradores civiles.

d) Congo: durante la misión en Angola un contingente militar cubano se desplegó en la región de Punta Negra, República del Congo, bajo la directriz de actuar como apoyo de las tropas que defendían Cabinda (Angola) de ser necesario.

e) Etiopía: codificada como Operación Baraguá, comenzó en enero de 1978 cuando llegaron a ese país las primeras tropas cubanas para enfrentar la agresión de las fuerzas armadas de Somalia, iniciada en julio de 1977. La misión se prolongó hasta septiembre de 1989 y en ella participaron 41.730 militares cubanos.

30 Cabe señalar que la injerencia de Cuba en la región del Medio Oriente fue más allá de lo documentado oficialmente, puesto que testimonios de ex combatientes israelíes de origen latinoamericano dan cuenta de la presencia permanente de asesores militares tanto en Siria como en el sur del Líbano durante la llamada guerra de desgaste (1967-1970), el propio conflicto armado de Yom Kippur e, incluso, con posterioridad a 1973; en el caso de la presencia cubana en el Líbano, en apoyo a diversos movimientos y corrientes de resistencia palestina, como lo atestiguan comunicaciones en idioma español con acento claramente caribeño. Lo que se desprende de testimonios de tres informantes clave, dos de origen argentino y uno de origen chileno, que sirvieron en Tzahal (Fuerzas de Autodefensa de Israel) y, por su dominio del idioma natal, fueron destinados a unidades del Aman (inteligencia militar) como intérpretes.

31 Bautizada así en homenaje a una negra cubana esclava que encabezó dos sublevaciones contra los españoles en el siglo XIX, siendo a la postre aprehendida y descuartizada. 
Adicionalmente, las FAR cumplieron misiones de colaboración militar (asesoramiento) en más de diez países. En todas estas misiones participó un total de 385.908 combatientes cubanos, de los cuales cayeron 2.398 efectivos.

Siguiendo a Domínguez, profesor de Harvard ${ }^{32}$ :

"De hecho, Cuba es el único país comunista capaz de desplegar sus fuerzas armadas miles de millas fuera de sus costas, para participar en guerras que estaban, en el mejor de los casos, remotamente relacionadas con la defensa de su suelo patrio; estas tropas, que luchan en las sabanas de Angola o en las estepas de Etiopía no estaban conformadas por checos, polacos, mongoles o búlgaros, sino por cubanos. A diferencia de las fuerzas armadas norteamericanas en Vietnam y las soviéticas en Afganistán, los cubanos ganaron las tres guerras que libraron en suelo africano: Angola 1975-1976; Etiopía 1977-1978; y Angola 1987-1988. Desde 1975 hasta 1989, Cuba mantiene más tropas desplegadas en los países africanos que las mantenidas por Estados Unidos en Vietnam durante el año cumbre de la guerra (1968)".

Sin embargo, una vez que Cuba queda desprovista del apoyo soviético y solo cuenta con los recursos propios de un país pequeño, deja de comportarse en la arena internacional como si fuera una potencia. Así, en septiembre de 1989, concluye la repatriación de sus tropas en Etiopía; en marzo de 1990 todo el personal militar cubano en Nicaragua es llevado de regreso a Cuba. En mayo de 1991 regresan de Angola las últimas tropas cubanas. Por lo tanto, al concluir la Guerra Fría y perder Cuba el apoyo militar y económico de la Unión Soviética, la presencia militar cubana llega a un fin casi instantáneo. Lo mismo ocurre con el apoyo cubano a los movimientos revolucionarios ${ }^{33}$.

De esta manera, el personal encuadrado en las FAR puede jactarse de tener experiencia en combate, factor cualitativo no material o intangible de primer orden del poder militar.

Aunque, más recientemente, se verifica injerencia militar cubana en países tales como Venezuela, Bolivia, Nicaragua y Ecuador, en el marco de la Alianza Bolivariana para las Américas (ALBA); así, el general retirado Antonio Rivero, ex colaborador de Chávez, reconoce que:

"[...] actualmente en el país hay más de 100.000 cubanos, entre ellos 3.700 funcionarios de su servicio de inteligencia, el G2. 'Nada más en seguridad y defensa, estimamos que puede haber unas 5.600 personas'. Y afirma que hay cubanos en las bases militares más importantes del país. 'En la Fuerza

32 DOMíNGUEZ, Jorge I., Las Relaciones cubano norteamericanas: de la Guerra Fría a la Guerra más Fría; en LOZANO, Wilfredo (editor) Cambio Político en el Caribe (Escenarios de la posguerra fría: Cuba, Haití y República Dominicana), Caracas, FLACSO, Nueva Sociedad, 1998, pp. 15 y 116.

33 Ibidem, pp. 117 y ss. 
Armada hay unos 500 militares activos cubanos que cumplen funciones de asesoría en áreas estratégicas: inteligencia, armamento, comunicaciones e ingeniería militar. También en el área operativa y en el despacho del ministro de la Defensa, que cuenta con un asesor cubano permanente con el grado de general'. Según el oficial, que trabajó como jefe de telecomunicaciones de la presidencia y fue director nacional de Protección Civil, la presencia de La Habana se remonta a 1997, cuando 29 agentes cubanos encubiertos se establecieron en Margarita y en 1998 ayudaron a Chávez en la campaña electoral en tareas de inteligencia, seguridad e informática. 'Los militares cubanos comienzan a llegar después de 2007. Su asesoría incluye un área educativa, de ingeniería militar en construcción de fortificaciones y en la doctrina, donde cambia el concepto de guerra planteado por el de la guerra asimétrica, que implica involucrar a la población civil en un sistema de defensa', explica el general"34.

Nueve meses antes, el entonces Ministro de Defensa venezolano, Diego Molero, defendió la asesoría militar que las Fuerzas Armadas de Venezuela reciben por parte de Cuba, señalando ${ }^{35}$ :

"[...] los militares venezolanos agradecen 'enormemente a los comandantes Fidel y Raúl Castro, a toda la Fuerza Armada Cuba y a su heroico pueblo' por transferirles experiencias acumuladas con la 'resistencia contra el imperio más nefasto que ha existido en la historia de la humanidad, que es el norteamericano'. A diferencia de lo sucedido en el pasado con 'la imposición de Estados Unidos (...), los cubanos son personas que, a pedido nuestro, vienen a proporcionarnos apoyo y nosotros vamos a darles apoyo, y nos apoyamos mutuamente como países hermanos', dijo el almirante durante una entrevista transmitida por el canal de televisión privado Televén. Molero resaltó que 'esas experiencias [cubanas] han sido de mucho valor para nosotros' y 'bienvenido el asesoramiento que Cuba nos da en pro del desarrollo de nuestra Fuerza Armada', si bien no dio otros detalles acerca del tipo de asesoría militar que brinda Cuba. Alrededor de 45.000 cubanos impulsan en Venezuela planes sociales gubernamentales, principalmente

34 Cabe señalar que Rivero solicita su baja en 2010 y denuncia ante la Fiscalía y la Asamblea Nacional la injerencia de Cuba en las Fuerzas Armadas con documentos, grabaciones y casi un centenar de fotografías. Acusado entonces de ultraje al Ejército y de "revelar noticia privada o secreta en grado de continuidad", actualmente se encuentra en libertad condicional. Ver; MARCANO, Cristina, Las relaciones desmedidas; en El País, 30 de marzo de 2014, disponible en, http://internacional.elpais.com/internacional/2014/03/28/ actualidad/1396026665_272257.html <consultado por última vez el 9 de marzo de 2015>.

35 Ver; LATINO (Alabama/Tennessee); http://www.latino-news.com/ministro-de-defensa-venezolano-aplaudeasesoria-militar-cubana/ <consultado por última vez el 9 de marzo de 2015>; también, ver EL DÍA, disponible en, http://eldia.com.do/gobierno-venezolano-recibe-asesoria-militar-de-cuba/ <consultado por última vez el 09 de marzo de 2015>; así como EL PAÍS http://www.elpais.com.co/elpais/internacional/noticias/ministrodefensa-venezuela-admitio-recibe-asesoria-militar-cuba <consultado por última vez el 9 de marzo de 2015> 
médicos y deportivos, y cuyos servicios son retribuidos, en parte, con el envío de 100.000 barriles diarios de crudo a la isla".

El lector se encuentra así frente a una cooperación militar cubana de nuevo cuño en el ámbito de los Estados miembros de ALBA y que responde fundamentalmente a los intereses nacionales de Cuba y, por ende, a la realpolitik.

c) Contribuyentes al desarrollo nacional: la misma Ley de la Defensa Nacional vigente, estipula que las FAR poseen una estructura que favorece el empleo de sus integrantes en actividades de provecho para el desarrollo económico-social del país y para la protección del medio ambiente. A las que se suman las misiones de apoyo, con el objeto de enfrentar y eliminar las consecuencias de los desastres naturales u otros tipos de catástrofes (protección o defensa civil), en las cuales el personal de sanidad militar juega un papel central.

De conformidad con Caroit ${ }^{36}$ a partir de 1994 las FAR redefinieron internamente su papel, decidiendo participar intensamente en el proceso de reformas del país; así, hacia 2005 el ejército cubano controlaba 322 empresas, que concentraba $89 \%$ de las exportaciones de la isla y de las que dependía el $20 \%$ de los asalariados.

\section{En síntesis y de conformidad con Da Silva y Johnson ${ }^{37}$ :}

"De esta forma, el ejército cubano, el más experimentado y cualificado de América Latina, se incorpora a los nuevos objetivos de la política exterior del país y también asume um mayor compromiso con los asuntos internos del país, principalmente en la prestación de servicios básicos y en la oferta de mano de obra cualificada y confiable en el desarrollo económico del país, con un despliegue de militares para funciones políticas y económicas en este período de recuperación. Esto porque, debido al colapso soviético, la nueva Ley de Defensa Nacional de 1994 determinó que la corporación debía satisfacer sus propias necesidades. De esta manera, las FAR lograron producir prácticamente la totalidad de los alimentos que consumían $<\ldots .>$ ocupando tierras ociosas <...> De esta forma, los militares cubanos emergen como gestores competentes, al contribuir al proceso de recuperación económica del país $<\ldots . .>$ verificándose así una modificación de su perfil; sin descuidar la defensa de la isla y de sus ideales revolucionarios, pasan a actuar en sectores que están directamente relacionados con el proceso de

36 CAROIT, J. M. Exército cubano controla 322 empresas; en, Folha de São Paulo, $n^{\circ}$ 28.249, Caderno Mundo, 9 de agosto de 2006; citado por Da Silva y Johnson, 2013, p. A15.

37 DA SILVA, Marcos Antonio y JOHNSON, Guillermo A., op.cit., p. 5. 
reinserción económica y, obviamente, acaban por transformarse en un actor relevante en la política interior y exterior $<\ldots$...".

Así lo reconoce González Mederos de la Arquidiócesis de La Habana ${ }^{38}$ :

"Otros dos datos de peso que vale la pena mencionar es el inmenso aparato económico que ha desarrollado la institución desde hace más de 20 años, que la ha llevado a tener un poderoso sistema empresarial. Este hecho propició el surgimiento de una clase empresarial emanada de la propia institución. Además, es posible palpar en el interior de las FAR un núcleo ideológico marcado por un nacionalismo pragmático, que avanza más allá del marxismo-leninismo".

Se trata de un rol que, siguiendo a la agencia de noticias EFE, encuentra sus orígenes a principios de la década de los años noventa ${ }^{39}$ :

"Durante el 'periodo especial', como se denomina al desplome económico tras la caída del bloque soviético, Raúl Castro impulsó un 'Sistema de Perfeccionamiento Empresarial' (SPE) que llevó a altos cargos del ejército a convertirse en verdaderos empresarios siguiendo modelos de eficiencia y competitividad aprendidos en escuelas internacionales de negocios. Este esfuerzo por establecer estructuras más eficientes, sin sobrepasar los límites de la propiedad estatal, convirtió a las FAR en gestores de los mayores 'holding' de la isla en sectores claves para la economía, como el turismo, el transporte o las comunicaciones. Al frente del mayor grupo empresarial de las FAR, el Grupo de Administración Empresarial S.A. (GAESA), se encuentra el general Julio Casas Regueiro, primer viceministro del Ministerio de las Fuerzas Armadas (Minfar). La Corporación Gaviota, un gigante del turismo que engloba una cadena hotelera, una aerolínea, una compañía de taxis, marinas, tiendas, restaurantes y museos, está bajo la dirección del general Luis Pérez Róspide. También el grupo turístico Cubanacán, fundado a principios de los 80 , está bajo dirección militar, como las Tiendas de Recaudación de Divisas (TRD), una importante fuente de ingresos en la moneda fuerte del país, el peso cubano convertible (CUC, equivalente a 1,08 dólares), y la Corporación de la Aviación Cubana (CACSA), encabezada por el general Rogelio Acevedo, solo por citar algunas de las compañías controladas por las FAR. Los militares dirigen, además, la política de otros

38 GONZÁLEZ Mederos, Lenier, op.cit., p. 2.

39 EFE, Las FFAA que lidera Raúl Castro son clave para el futuro de Cuba; disponible en, http://www.infobae. com/2006/08/17/271657-las-ffaa-que-lidera-raul-castro-son-clave-el-futuro-cuba <consultado por última vez el 9 de marzo de 2015> Para una visión crítica sobre el particular; ver Turismo paramilitar, en DIARIO DE CUBA, disponible en: http://www.diariodecuba.com/cuba/1414268063_10973.html <consultado por última vez el 9 de marzo de 2015>. 
importantes sectores, como la pesca, la marina mercante y el Ministerio del Azúcar, bajo el mando del general Ulises Rosales del Toro, un hombre muy próximo a Raúl Castro. En conjunto, las FAR manejan más de 300 empresas que generan alrededor del 80 por ciento de las exportaciones y buena parte de los ingresos por turismo y servicios, según cálculos extraoficiales".

Recapitulando, la situación actual del instrumento militar cubano es sintetizada de la siguiente manera por Veiga González ${ }^{40}$ :

"Las FAR constituyen la institución más fuerte, cohesionada y profesional del actual sistema, no está directamente comprometida con vejaciones, goza del respeto de muchos ciudadanos, es nacionalista y se siente -según tengo entendido- muy comprometida con el desarrollo armónico de la nación".

Sin embargo, el lector se encuentra ante un proceso de desmilitarización de las FAR que apuestan por una expansión de su rol para invadir otras esferas que las alejan de la profesión militar. La dimensión empresarial de los militares contribuye a su desnaturalización y pone en entredicho la preparación y aprestamiento del instrumento castrense para la defensa nacional ${ }^{41}$.

d) Nuevas amenazas, como el narcotráfico: en virtud del cual las FAR han establecido vínculos con el Comando Sur de Estados Unidos e, incluso, llevado a cabo maniobras combinadas. A partir de 1995, los militares cubanos y estadounidenses apostados a ambos lados de la zona minada que rodea la base naval de Guantánamo, así como los servicios de guardacostas y guardafronteras empiezan a cooperar en la búsqueda, rescate y devolución de balseros indocumentados e, incluso, en acciones puntuales contra el narcotráfico. Posteriormente, en 1997, el Pentágono y las agencias de inteligencias norteamericanas, certifican que Cuba deja de representar una amenaza militar para Estados Unidos ${ }^{42}$.

40 VEIGA González, Roberto, Las FAR ante los retos de una nueva realidad social; en, Espacio Laical (Suplemento Digital de la Arquidiócesis de La Habana), marzo de 2013, p. 3.

41 Así en un sitio web oficial puede leerse, bajo el título Visión General: "Las FAR poseen una estructura, equipamiento y preparación que garantiza el cumplimiento de sus misiones combativas y además permite el empleo de sus integrantes en actividades de provecho para el desarrollo económico del país y para la protección del medio ambiente"; disponible en, http://www.ecured.cu/index.php/FAR <consultada por última vez el 7 de mayo de 2014> También, se recomienda consultar; MORA, Leonardo, Normalization of U.SCuban Relations (December 2014): Will Cuba transition to capitalism?, en la Quora, disponible en, http:// www.quora.com/Normalization-of-U-S-Cuban-Relations-December-2014/Will-Cuba-transition-to-capitalism $<$ consultado por última vez el 7 de marzo de 2015>.

42 HERNÁNDEZ, Rafael, Cuba versus la cuestión de la Democracia; en, Revista Nueva Sociedad, N²16, ¿Cuba cambia?, julio-agosto 2008, Buenos Aires, p. 157. 
Esto tiene un impacto sobre los sistemas de armas de las FAR; por ejemplo, tratándose de la Armada, se prescinde de los principales medios de combate, los submarinos y las fragatas de fabricación soviética, que son sustituidos por una corbeta (PAUK II), una patrullera de altamar (Tipo 390) y cuatro buques de ataque rápido (OSA II) de mucho menor porte, autonomía y calado. Esto trae aparejada la pérdida de capacidades operacionales, al transformarse en una green water navy, de acuerdo con la doctrina naval británica ${ }^{43}$. Se asumen nuevos roles de preservación de la zona económica exclusiva, velar por la vida humana (balseros y migrantes), la lucha antinarcóticos en la mar y el desarrollo de una incipiente industria naval propia.

De esta manera, Jane's destaca la adaptación de la Armada a esos nuevos roles, con la reciente construcción de tres embarcaciones interceptoras rápidas (Tipo FLECHA) y la reconversión de un buque pesquero de arrastre en un buque patrullero oceánico con helicóptero embarcado, en sus propios astilleros ${ }^{44}$.

Principales Medios de la Marina de Guerra Revolucionaria, 1992 - 2012

\begin{tabular}{|l|c|c|}
\hline Buques / Años & $\mathbf{1 9 9 2}$ & $\mathbf{2 0 1 2}$ \\
\hline Submarinos Clase Foxtrot & 2 & -- \\
\hline Fragatas Clase Koni & 3 & --- \\
\hline Dragaminas & 16 & 2 \\
\hline Patrulleros costeros & 28 & 20 \\
\hline
\end{tabular}

Fuente: THE INTERNATIONAL INSTITUTE FOR STRATEGIC STUDIES, The Military Balance, 1992 y 2012 ; JANE'S SENTINEL COUNTRY RISK ASSESSMENTS, Cuba Navy Assessment, Jane's, London, 2013.

\section{Escenarios a futuro ${ }^{45}$}

El probable restablecimiento de relaciones diplomáticas entre Cuba y Estados Unidos altera significativamente el papel de las FAR. Efectivamente, el 14 de diciembre de $2014^{46}$, Raúl Castro Ruz y Barack Obama hacen público el inicio de conversaciones para restablecer las relaciones diplomáticas interrumpidas durante más de medio siglo. Se trata de una declaración conjunta que contiene 13

43 Para mayores detalles; ver, Dalton, 2006 y Tangredi, 2002.

44 JANE'S SENTINEL COUNTRY RISK ASSESSMENTS, Cuba Navy Assessment, Jane's, London, 2013.

45 La metodología para la construcción de los escenarios a futuro, por parte del autor, se tomó de; UNIVERSIDAD DE GUADALAJARA, Jalisco a Futuro 2012-2032 Construyendo el porvenir, Informe de prospectiva, Guadalajara, Centro de Estudios Estratégicos para el Desarrollo, 2013, volumen 7.

46 Texto del Comunicado de Raúl Castro Ruz, Alocución del presidente cubano,; disponible en: http://www. cubaminrex.cu/es/alocucion-del-presidente-cubano <consultado por última vez el 7 de marzo de 2015>. 
puntos sobre el establecimiento de relaciones diplomáticas, temas económicos, viajes, comunicaciones, frontera marítima y derechos humanos, entre los más relevantes. Como consecuencia de lo cual, el 12 de enero de 2015 Cuba libera a 53 presos políticos y ambos Estados soberanos dejan en libertad a prisioneros sentenciados por haber llevado a cabo labores de inteligencia ${ }^{47}$. Diez días después de ambos gestos de buena voluntad, funcionarios estadounidenses y cubanos se reúnen en La Habana con el objeto de debatir cuestiones de interés común entre Estados Unidos y Cuba ${ }^{48}$.

En palabras de un profesor de la American University de Washington, D.C. ${ }^{49}$ :

"Cuba ha tenido una mentalidad de fortaleza sitiada porque ha estado bajo asedio. Quizás la normalización de relaciones entre Cuba y los Estados Unidos conduzca hacia una normalización del debate político y la discrepancia en Cuba".

No obstante, más allá de esta significativa alteración de las relaciones bilaterales Cuba-Estados Unidos y su posible impacto sobre la política de defensa y las FAR, González Mederos pone de relieve el peso que la conducción militar tiene sobre el futuro político de la isla, a la luz de su integración al máximo órgano de decisión política ${ }^{50}$ :

"De los 15 miembros del Buró Político elegidos en el VI Congreso del PCC, 10 fueron militares. Con la muerte del general Julio Casas Regueiro ahora son nueve. Dos tercios del máximo órgano de poder del país corresponde a personas vinculadas a las FAR, incluyendo a cuatro de sus generales más importantes, a quienes corresponderá, dentro de muy poco tiempo, tomar decisiones cruciales sobre el destino de Cuba: Leopoldo Cintra Frías (ministro de las FAR y una leyenda viva de las guerras africanas); Abelardo Colomé Ibarra (ministro del Interior, quien alcanzó los grados de comandante, con apenas 20 años, en el Segundo Frente Oriental); Álvaro López Miera

47 Ver, por ejemplo; Declaración de Prensa John Kerry Secretario de estado Washington, DC 17 de diciembre 2014; en http://www.state.gov/documents/organization/235582.pdf <consultado por última vez el 9 de marzo de 2015>.

48 Para Estados Unidos, esta sesión bilateral extendida incluye un diálogo constructivo y alentador; al tratarse temas tales como el tráfico de personas, la aplicación de la ley, la protección medioambiental, las telecomunicaciones y la seguridad de la salud mundial, así como respuestas coordinadas a los derrames de petróleo y el Ébola, al tiempo que se hace hincapié en la necesidad de mejorar las condiciones de los derechos humanos en Cuba, incluida la libertad de expresión y de reunión; para mayores detalles ver, http:// www.state.gov/documents/organization/236437.pdf <consultado por última vez el 9 de marzo de 2015>.

49 LEOGRANDE, William, EI 17D: secuencias y consecuencias (I), Entrevista; disponible en, http://temas.cult. cu/blog/?p=1805 <consultado por última vez el 9 de marzo de 2015> También, ver; Cuba Debate, disponible en, http://www.cubadebate.cu/especiales/2015/01/07/el-17d-secuencias-y-consecuencias-william-leogrande/\#. VP3aql6zlx8 <consultado por última vez el 9 de marzo de 2015>.

50 GONZÁLEZ Mederos, Lenier, op.cit., p. 2. 
(viceministro primero de las FAR, jefe de su Estado Mayor, muy cercano y querido por Raúl Castro, pues siendo casi un niño se incorporó a las filas del Segundo Frente), y Ramón Espinosa Martín (viceministro de las FAR, muy respetado por la organización, casi de relojería suiza, que supo imprimirle al Ejército Oriental, bajo su mando durante muchos años)".

Lo anterior se explica por la fidelidad de las FAR al Partido Comunista de Cuba, tal como se destaca en un sitio web oficial ${ }^{51}$.

En contraste, para un profesional de las armas cubano ${ }^{52}$ :

"Con la despolitización y con la eliminación de los temas dirigidos a la enseñanza del comunismo como doctrina social correcta se logra el objetivo de la profesionalización de las fuerzas armadas".

Sin embargo, no debería soslayarse que las fuerzas armadas, en tanto institución, se encuentran subordinadas al poder político (léase, al régimen político); por lo que, en lo que al futuro del instrumento militar de Cuba se refiere, es posible vislumbrar tres escenarios para la próxima década, que dependerán del derrotero de la dimensión política al que se encuentra subordinado ${ }^{53}$, a saber:

\section{a) Escenario 1}

El régimen político cubano se mantendrá incólume, no obstante su innegable proceso de desgaste y el giro de 180 grados en las relaciones bilaterales con Estados Unidos; y, por ende, las fuerzas armadas revolucionarias de Cuba se consolidarán como uno de sus principales pilares; máxime al ocupar sus mandos superiores posiciones clave en los mecanismos de conducción política de la isla. Dicho en otros términos, el brazo armado surgido del movimiento revolucionario que depuso al régimen encabezado por Fulgencio Batista, continuará desempeñando su papel tradicional de símbolo de un sistema político de naturaleza socialista, que goza de legitimidad y bases sociales de apoyo en el ejercicio del poder, con una doctrina de guerra basada en la defensa popular total a partir de un cuerpo de oficiales de elevado grado de escolaridad promedio, alto nivel profesional, y un comando con experiencia en combate durante su trayectoria como oficiales subalternos.

51 Ver, http://www.ecured.cu/index.php/FAR <consultada por última vez el 7 de mayo de 2014>.

52 José Quevedo, general retirado, ocupa la dirección de la Escuela Superior de Guerra y se desempeña como Agregado Militar de la Embajada de Cuba en la Unión Soviética, entre otras funciones. Desde hace varios años reside en Estados Unidos; ver YÁÑEZ, Eugenio, Cuando brillan las estrellas; en, Cubanálisis EI Think-Tank; disponible en, http://www.cubanalisis.com/ART\%CDCULOS/EUGENIO\%20-\%20CUANDO\%20 BRILLAN\%20LAS\%20ESTRELLAS.htm <consultado por última vez el 9 de marzo de 2015>.

53 CLAUSEWITZ, Karl von, op. cit., Tomo III: Libro VIII, Capítulo VI. 
La carrera militar, particularmente el escalafón de la oficialidad, seguirá gozando de la confianza de la conducción política, de prestigio relativo y jugando como canal de movilidad social, por lo que se mantendrán abiertas las escuelas de formación de suboficiales, especialistas y mandos, sin descuidar el adoctrinamiento político; a lo que se sumará la internacionalización con sendos intercambios con pares de terceros países, entre los que destacará la República Popular China y la Rusia de Putin, a partir de convenios suscritos.

A la luz del perfil de sus cuadros profesionales y de la lealtad incondicional al régimen y liderazgo político, continuarán desempeñando roles no tradicionales en ministerios y dependencias alejadas de la tradicional concepción de la defensa nacional, particularmente en el Ministerio del Interior (MININT), incluyendo inteligencia interna y mecanismos de control de la disidencia, y en el Ministerio de Turismo, como antídoto a la corrupción y preservación de la principal fuente de ingresos del Estado. Paralelamente, se alentará la salida empresarial para muchos militares que, por su perfil y disciplina, encontrarán una canalización lucrativa que contribuirá a la generación de riqueza pero que, a la vez, los alejará del mundo castrense.

En síntesis, un escenario de este tipo traerá aparejado, en los próximos diez años, la continuidad del componente militar -en especial el ejército- como institución básica o fundamental y soporte clave de un régimen político único en el hemisferio y de los pocos que aun existen en el orbe.

\section{b) Escenario 2}

No obstante la legitimidad y las bases sociales de apoyo de las que todavía gozará el régimen político cubano, en la próxima década se harán presentes, cada vez con mayor regularidad e intensidad, conflictos sociales y movimientos contestatarios que obligarán a los tomadores de decisiones a apostar por medidas de carácter represivo-punitivo y endurecimiento de las posiciones oficiales en un juego suma cero a favor del socialismo cubano. En este marco de sobrevivencia de la experiencia cubana a cualquier costo, las fuerzas armadas abiertamente se convertirán en el perro guardián de la revolución, al apoyar abiertamente al liderazgo político y participar activamente en el control de la disidencia por la fuerza en misiones y funciones de naturaleza policial y parapolicial de carácter interno. Así, el ejército asumirá responsabilidades de control social en el frente interno que incluirán labores de inteligencia y seguimiento a la delación de probables contrarrevolucionarios, así como de vigilancia y seguridad de centros de reclusión, en especial los que albergan a presos políticos.

En el ámbito de la defensa nacional y ante el fracaso del diálogo con Estados Unidos, dominará la mentalidad de fortaleza sitiada y del imperialismo estadounidense como la principal amenaza a la seguridad nacional cubana, lo que 
por un lado buscará contribuir a la legitimidad del régimen político y, por otro, a consolidar fuerzas armadas basadas en la defensa territorial, el sistema de milicias, la fabricación y mantenimiento de sistemas de armas propios y un elevado gasto de defensa y nivel de militarización social en comparación con sus pares de la región.

Las lealtades políticas se impondrán sobre el profesionalismo y la trayectoria del personal encuadrado; esto será más claro tratándose de oficiales y mandos superiores. Por ser las fuerzas armadas una institución de tipo piramidal o jerárquico, el régimen político apostará por un mayor control y sujeción de los coroneles y generales, quienes pasarán rigurosa y regularmente por el tamiz político-ideológico.

Recapitulando, bajo este escenario, en la década por venir el ejército constituirá uno de los principales puntales de un régimen político anacrónico, capaz de sacrificar en el altar de la seguridad nacional cualquier tipo de derechos y libertades públicas o críticas -por mínimas que sean, se considerarán amenazas reales a la seguridad nacional- al socialismo cubano; instrumento coercitivo de control social y político, el perfil de las fuerzas armadas se acercará más al de fuerzas de seguridad o intermedias (paramilitay forces) e incluso policiales, que a militares propiamente dichas.

\section{c) Escenario 3}

Tras una transición del régimen de partido único a un incipiente Estado de Derecho democrático, una nueva clase política asumirá el poder, hará tabla rasa de todo aquello relacionado con el régimen castrista y comenzará un verdadero ajuste de cuentas con los operadores del socialismo cubano. De ahí que las fuerzas armadas serán, sin lugar a dudas, uno de los principales objetivos a transformar, lo que implicará la desaparición del escalafón de oficiales políticos y la realización de una verdadera purga entre los militares de carrera. En principio serán removidos o pasados a retiro todos los oficiales superiores de las fuerzas armadas y la institución se retirará de todas aquellas labores alejadas de la profesión militar, es decir, de su área competencial. El ejército sufrirá así un proceso de reforma en consonancia con los cambios en la dimensión política, y quedará constreñido a las funciones de defensa nacional y apoyo a la política exterior cubana de nuevo cuño; lo cual tendrá como significado la cada vez más activa participación en operaciones de paz bajo el mandato de la Organización de Naciones Unidas (ONU), integrando componentes de los denominados cascos azules y probablemente comenzando con Haití por su cercanía geográfica y la experiencia latinoamericana de fuerzas combinadas.

El gasto militar y las dimensiones de las fuerzas armadas sufrirán un proceso draconiano de reducción, abandonándose la doctrina de la defensa popular 
total y apostándose por la calidad en detrimento de la cantidad; asimismo, el ejército de masa de conscriptos será sustituido por un ejército de voluntarios, es decir, de soldados profesionales. El recambio generacional y la integración de cubanos exiliados en las filas del nuevo ejército, contribuirán a transformar de arriba abajo a esta institución básica del Estado.

Los mandos y el personal del ejército cubano romperán sus tradicionales vínculos con la Federación Rusa, Irán, Venezuela y China continental, para entablar relaciones e intercambios con las fuerzas armadas de la región, Estados Unidos y demás integrantes de la OTAN, en la construcción de una nueva doctrina militar acorde con los tiempos políticos democráticos. Del mismo modo, romperán todo tipo de contacto con fuerzas armadas de países considerados no democráticos así como con movimientos de naturaleza terrorista de acuerdo con los parámetros del mundo occidental.

La velocidad e intensidad de dicho proceso de transformación, dependerá de la posición que adopten las FAR de Cuba sobre el futuro del sistema político de la isla: a) escalonado o gradual, de facilitar la reforma de la institucionalidad republicana, como facilitadoras de un diálogo nacional ampliado e incluyente; b) radical o de tabla rasa, de defender a ultranza al régimen político y obstaculizar el tránsito a un Estado democrático de Derecho.

En síntesis, las fuerzas armadas en tanto institución y los hombres y mujeres que las encarnan, serán sometidos a un proceso de transformación y modernización, cuyos contenidos y alcances estarán sujetos a lo que hagan o dejen de hacer los propios uniformados; en contraste con la expansión del papel del ejército característico de los escenarios tendencial y pesimista, la próxima década traerá como reto el desarrollo de una democracia liberal y de fuerzas armadas al servicio de la misma.

\section{A manera de conclusiones: papel de las FAR en el futuro del sistema político de Cuba}

Las FAR de Cuba, como su nombre lo pone de relieve, surgen de un movimiento revolucionario que hace tabla rasa del instrumento militar del régimen de Fulgencio Batista. Posteriormente, sufren un proceso de modernización bajo el molde soviético para, en el marco de la posguerra fría y la crisis económica, adaptarse a nuevos roles y asumir nuevas responsabilidades.

Mientras que, a la par de la expansión del papel de las FAR -especialmente en el mundo empresarial-se constata una pérdida de sus capacidades, tanto en efectivos encuadrados como en medios o sistemas de armas. En otros términos y tal como se pone de relieve en párrafos anteriores, la dimensión empresarial de los militares contribuye a su desnaturalización y pone en entredicho la preparación y aprestamiento del instrumento castrense para la defensa nacional. 
Adicionalmente, no debe soslayarse que las mismas se encuentran inextricablemente unidas al sistema político que les dio vida y que su lealtad es, precisamente, con el Partido Comunista de Cuba.

Comoquiera que sea, las FAR constituyen un actor clave en el presente y, sobre todo, en el futuro de Cuba; su fortaleza, profesionalismo y compromiso permiten así esbozar tres escenarios a futuro. Del resultado del proceso de decisiones de quienes ejercen su comando dependerá, en gran medida, el futuro de la isla.

En tanto que, para el resto de América Latina y el Caribe, el estudio comparado de las FAR de Cuba contribuye a:

1) reconocer que, independientemente del régimen político dominante, del nivel socioeconómico de la población y del tipo de sociedad a considerar, las fuerzas armadas se erigen en una institución básica del EstadoNación, responsable de velar por la defensa nacional y la preservación de la soberanía e integridad territorial. El instrumento militar encarna, de esta manera, el monopolio estatal sobre la guerra. Solo en los denominados "Estados fallidos" (failed states), como Haití en nuestro hemisferio, el lector se encuentra ante la ausencia de fuerzas armadas y, por ende, de ejércitos privados que suelen ocupar este vacío ${ }^{54}$;

2) tomar conocimiento que, tratándose de un régimen político de partido único, como el cubano, no es posible para los militares diferenciar y separar la dimensión política de la técnica o profesional propiamente dicha. En otras palabras, el peso de la política -de la mano del Partido Comunista Cubano- se hace sentir en las FAR en tanto institución. Esto significa que el aspecto ideológico cobra una mayor relevancia y trascendencia que en el caso de las fuerzas armadas de países con tradición democrática, entendida esta como la democracia indirecta o liberal;

3) no obstante esta situación propia de regímenes políticos como el cubano55, las FAR de Cuba no escapan a la transición que, como tendencia, se impone en las fuerzas armadas de Latinoamérica y que puede sintetizarse en la expansión de su rol o papel a la luz de los retos de la mano del fenómeno de la globalización y la debilidad del aparato estatal. La fortaleza que, en general, caracteriza a las fuerzas armadas y el profesionalismo que suelen presentar los militares en la región, constituyen una tentación para los

54 Incluso en países como Costa Rica y Panamá, aunque oficialmente no existan fuerzas armadas, cuentan con instrumentos coercitivos, poder de fuego y capacidades de defensa similares a la ultima ratio del Estado.

55 En este marco, cabe recordar la figura del comisario político en las fuerzas armadas de la entonces Unión de Repúblicas Socialistas Soviéticas, que tuvo su mayor apogeo durante la denominada "Gran Guerra Patriótica" (1941-1945), que no fue sino el teatro de operaciones o frente oriental de la segunda conflagración mundial. 
políticos de turno que llegan a empeñarlos en misiones y funciones que no son de su propia naturaleza, frente a la debilidad de otras instituciones estatales como la policía.

En rigor, se puede concluir con el reconocimiento de que el futuro, no solo de Cuba, sino del resto de los países del subcontinente, depende en gran medida de ese actor clave que son sus fuerzas armadas y los hombres y mujeres que lo encarnan y vivifican; aunque tratándose de esa isla del Caribe se hace sentir más el peso de sus FAR sobre el devenir del proceso político nacional, a la luz de su propia naturaleza y de la expansión del rol de sus militares. 


\section{Fuentes consultadas}

ABREU, Ricardo, Power and Politics in International Relations Theories: $A$ Strategic Framework Approach. European and International dimension of policy-making Professor Michael Bauer, Instituto Universitário de Lisboa, January 2013. Disponible en; http://es.scribd.com/doc/122657199/Powerand-Politics-in-International-Relations-Theories-A-Strategic-FrameworkApproach <consultado por última vez el 18 de agosto de 2013>.

BEAUFRE, André, La Estrategia en el modo de acción, Buenos Aires, Pleamar, 1973.

CAROIT, J. M. Exército cubano controla 322 empresas; en, Folha de São Paulo, $\mathrm{n}^{\circ}$ 28.249, Caderno Mundo, pag. A15, 9 de agosto de 2006; citado por Da Silva y Johnson, 2013, p.13.

CLAUSEWITZ, Karl von, De la Guerra (III). Libro VIII, "Plan de una guerra" Capítulo VI, "Influencia del objetivo político sobre el propósito militar" y "La guerra como instrumento de la política"; pp. 349-359, México, Editorial Diógenes, S.A., 1973.

CORONEL (R) SAUTIÉ Mohedano, Pedro y Teniente Coronel PÉREZ San Miguel, Alfredo, Misiones militares internacionalistas cumplidas por las Fuerzas Armadas Revolucionarias de la República de Cuba; en CUBA DEFENSA (2012), $\quad$ http://www.cubadefensa.cu/?q=misiones-militares\&b=d3 <consultado por última vez el 18 de agosto de 2013>.

DA SILVA, Marcos Antonio y JOHNSON, Guillermo A. As Forças Armadas Revolucionárias cubanas (FAR) e o mundo pós guerra-fria: um caso excepcional?, trabajo inédito y aceptado para ser publicado por una revista universitaria, proporcionado por Marcos Antonio da Silva, Profesor de Ciencia Política de la Universidade Federal do Rio Grande do Norte, Brasil, 2013.

DALTON, Jane G., Future navies - present issues, Naval War College Review, USA, Winter 2006; disponible en, http://findarticles.com/p/articles/mi_ m0JIW/is_1_59/ai_n26780463/<consultado por última vez el 2 de julio de 2013>.

DOMÍNGUEZ, Jorge I., Las Relaciones cubano norteamericanas: de la Guerra Fría a la Guerra más Fría; en LOZANO, Wilfredo (editor) "Cambio Político en el Caribe" (Escenarios de la posguerra fría: Cuba, Haití y República Dominicana), Caracas, FLACSO, Nueva Sociedad, 1998, pp. 115 y 116.

DOMÍNGUEZ, Jorge, I., La política exterior de Cuba y el sistema internacional; en, TULCHIN, Joseph y ESPACH, Ralph. "América Latina en el nuevo sistema internacional”, Barcelona, Bellaterra, 2004, pp. 255-286. 
ECURED, Fuerzas Armadas Revolucionarias de Cuba; disponible en, http://www. ecured.cu/index.php/FAR <consultado por última vez el 7 de mayo de 2014>.

EFE, Las FFAA que lidera Raúl Castro son clave para el futuro de Cuba; disponible en, http://www.infobae.com/2006/08/17/271657-las-ffaa-que-lidera-raulcastro-son-clave-el-futuro-cuba <consultado por última vez el 9 de marzo de 2015>.

GARCÍA Covarrubias, Jaime. Transformación de la Defensa: El Caso de EE.UU. y su Aplicación en Latinoamérica; en, Military Review, The Professional Journal of the U.S. Army, Edición Hispanoamericana, Fort Leavenworth, Kansas, U.S. Army Combined Arms Center, marzo-abril 2005; pp. 23-30.

GOBIERNO DE LA REPÚBLICA DE CUBA, Constitución de la República de Cuba, La Habana, Cuba Debate, 2013; disponible en, http://www.cubadebate. cu/cuba/constitucion-republica-cuba/ <consultado por última vez el 18 de agosto de 2013>.

GOBIERNO DE LA REPÚBLICA DE CUBA, Doctrina Militar Cubana; disponible en, http://www.cubagob.cu/otras_info/minfar/doctrina/doctrina_militar.htm <consultado por última vez el 18 de agosto de 2013>.

GOBIERNO DE LA REPÚBLICA DE CUBA, Fuerzas Armadas Revolucionarias; disponible en, http://www.cubagob.cu/otras_info/minfar/far/pfar.htm <consultado por última vez el 18 de agosto de 2013>.

GOBIERNO DE LA REPÚBLICA DE CUBA, Fundamentos de la Defensa Nacional; disponible en, http://www.cubagob.cu/otras_info/minfar/fundamentos/ fundamentos1.htm <consultado por última vez el 7 de marzo de 2015>.

GOBIERNO DE LA REPÚBLICA DE CUBA, La Ley No 75 de la Defensa Nacional, La Habana, Cuba Defensa, 2012l; disponible en, http://www.cubadefensa. cu/?q=ley75<consultado por última vez el 18 de agosto de 2013>.

GONZÁLEZ Mederos, Lenier, Las fuerzas armadas y el futuro de Cuba; en, Espacio Laical (Suplemento Digital de la Arquidiócesis de La Habana), número 224, marzo de 2013, pp. 1-3.

HERNÁNDEZ, Rafael, Cuba versus la cuestión de la Democracia; en, Revista Nueva Sociedad, $\mathrm{N}^{\circ}$ 216, ¿Cuba cambia?, julio-agosto 2008, Buenos Aires, pp. 157 y ss.

JANE'S SENTINEL COUNTRY RISK ASSESSMENTS, Cuba Navy Assessment, Jane's, London, 2013. 
JUVENTUD REBELDE, Camilo Cienfuegos: fuerza y pasión de su pensamiento revolucionario, 24 de octubre de 2014; disponible en, http://www. juventudrebelde.cu/cuba/2014-10-24/camilo-cienfuegos-fuerza-y-pasionde-su-pensamiento-revolucionario/ <consultado por última vez el 7 de marzo de 2015>.

KLEPAK, Hal, Cuba's Military 1990-2005: Revolutionary Soldiers during CounterRevolutionary Times, London, Palgrave Macmillan, 2005; en particular, Chapter 9 The Military Defense of Cuba: But Can the FAR still Deter?, pp. 241-270.

KNORR, Klaus E., El poder de las naciones, Buenos Aires, Editorial de Belgrano, 1981.

LEOGRANDE, William, El 17D: secuencias y consecuencias (I), Entrevista; disponible en, http://temas.cult.cu/blog/?p=1805 <consultado por última vez el 9 de marzo de 2015> También, ver; http://www.cubadebate.cu/ especiales/2015/01/07/el-17d-secuencias-y-consecuencias-williamleogrande/\#.VP3aql6zlx8 <consultado por última vez el 9 de marzo de 2015>.

MARCANO, Cristina, Las relaciones desmedidas; en El País, 30 de marzo de 2014, en, http://internacional.elpais.com/internacional/2014/03/28/ actualidad/1396026665_272257.html <consultado por última vez el 9 de marzo de 2015>.

MOLOEZNIK, Marcos Pablo, Seguridad y uso de la fuerza en el Estado contemporáneo (una interpretación mexicana sobre los instrumentos coercitivos estatales); en, Revista del Centro de Estudios Latinoamericanos (CESLA), Universidad de Varsovia, (6) 2004, pp. 29-36.

MOLOEZNIK, Marcos Pablo, El devenir histórico de los militares y la seguridad nacional en América Latina (De la profesionalización a la doctrina de la seguridad nacional); en, KRZYWICKA Katarzyna (coordinadora y editora), "Bicentenario de la Independencia de América Latina (cambios y realidades)", Lublin, Editorial de la Universidad Maria Curie-Sklodowska (UMCS), 2012, pp. 95-118.

MOLOEZNIK, Marcos Pablo, Las fuerzas armadas revolucionarias de Cuba: entre el pasado y el futuro; en, DEMBICZ, Katarzyna (editora) "Cuba: ¿quo vadis?", Centro de Estudios Latinoamericanos (CESLA) de la Universidad de Varsovia, Colección Estudios y Memorias 45, Varsovia 2013, pp. 149166. 
MURRAY, Douglas J. \& VIOTTI, Paul R., The Defense Policies of Nations (A Comparative Study), Baltimore and London, The Johns Hopkins University Press, 1994.

NYE Jr, Joseph. S., Get Smart-Combining Hard and Soft Power. Foreign Affairs, 2009, pp. 88-160.

OROZCO, Román, Cuba Roja (Cómo viven los cubanos con Fidel Castro), Buenos Aires, Javier Vergara, 1993.

STERN, Frederick Martin, El Ejército Ciudadano, Biblioteca del Oficial, Volumen 509, Buenos Aires, Círculo Militar, 1961.

TANGREDI, Sam J. Ed., Globalization and Maritime Power, Washington, D.C., Institute for National Strategic Studies and National Defense University, 2002.

THE INTERNATIONAL INSTITUTE FOR STRATEGIC STUDIES, The Military Balance 1992-1993, Chapter Eight: Latin America and the Caribbean, London, Brassey's, Autumn 1992.

THE INTERNATIONAL INSTITUTE FOR STRATEGIC STUDIES, The Military Balance 2012-2013, Chapter Eight: Latin America and the Caribbean, London, Routledge, Version of record first published: 7 Mar 2012.

UNIVERSIDAD DE GUADALAJARA, Jalisco a Futuro 2012-2032 Construyendo el porvenir, Informe de prospectiva, Guadalajara, Centro de Estudios Estratégicos para el Desarrollo, 2013, volumen 7.

VEIGA González, Roberto, Las FAR ante los retos de una nueva realidad social; en, Espacio Laical (Suplemento Digital de la Arquidiócesis de La Habana), marzo de 2013, pp. 3 y ss.

YÁÑEZ, Eugenio, Cuando brillan las estrellas; en, Cubanálisis El ThinkTank; disponible en, http://www.cubanalisis.com/ART\%CDCULOS/ EUGENIO\%20-\%20CUANDO\%20BRILLAN\%20LAS\%20ESTRELLAS. $\mathrm{htm}<$ consultado por última vez el 9 de marzo de 2015>. 